\title{
The Influence of Oral Ginger before Operation on Nausea and Vomiting after Cataract Surgery under General Anesthesia: A double-blind placebo-controlled randomized clinical trial
}

\author{
Jamal Seidi ${ }^{1}$, Shahrokh Ebnerasooli ${ }^{2}$, Sirous Shahsawari ${ }^{3}$, Simin Nzarian $^{4}$
}

${ }^{1}$ Ph.D. of Nursing, Assistant Professor, Department of Operating Room, Faculty of Nursing and Midwifery, Kurdistan University of Medical Sciences, Sanandaj, Iran

${ }^{2}$ Board of Anesthesia, Assistant Professor, Department of Anesthesia, Faculty of Medical, Kurdistan University of Medical Sciences, Sanandaj, Iran

${ }^{3}$ M.Sc. of Epidemiology, Department of Public Health, Faculty of Health, Kurdistan University of Medical Sciences, Sanandaj, Iran

${ }^{4}$ M.Sc. of Nursing, Department of Operating Room, Faculty of Nursing and Midwifery, Kurdistan University of Medical Sciences, Sanandaj, Iran

Type of article: Original

\begin{abstract}
Background: According to Iranian traditional medicine, using safe ginger may contribute to taking less chemical medicines and result in fewer side effects.

Objective: To determine the influence of using ginger before operation on nausea and vomiting, after cataract surgery under general anesthesia.

Methods: This study was a double-blind placebo-controlled randomized clinical trial conducted at Kurdistan University of Medical Sciences in 2015. 122 candidates of cataract surgery were randomly allocated in three groups. The first group received a ginger capsule in a single $1 \mathrm{~g}$ dose, the second received two separate doses of ginger capsule each containing $500 \mathrm{mg}$ and the third group received placebo capsule before operation. The patients were examined and studied for the level of nausea and occurrence of vomiting for 6 hours after the operation. The intensity of nausea was scored from zero to ten, based upon Visual Analog Scale. SPSS version 20 was used to analyze the data. We used Chi square and Kruskal-Wallis test for the analyses of outcomes.

Results: The frequency and intensity of nausea and the frequency of vomiting after operation among those who had taken the ginger capsule in 2 separate $500 \mathrm{mg}$ doses was less than the other 2 groups. This difference was significant $(\mathrm{p}<0.05)$.

Conclusion: As the results of the study indicated, using ginger as safe medicine, which could act complementary to chemical medicines was really useful in reducing the frequency and intensity of nausea and vomiting after cataract surgery. As this study found, the maximum efficiency of ginger was when it had been taken regularly and constantly in separate doses.

Trial Registration: The trial was registered at the Iranian Registry of Clinical Trials (http://www.irct.ir) with the Irct ID: IRCT2015062122853N1

Funding: This research was supported by the research cluster grant (93/132) from Kurdistan University of Medical Sciences, Sanandaj, Iran.

Keywords: Ginger, Operation, Nausea, Vomiting, Cataract, General anesthesia
\end{abstract}

\section{Introduction}

Post-operation nausea and vomiting (1) is observed in 20 to 70 percent of all operations $(2,3)$. These complications can open surgical stitches, increase the pressure inside the eye and skull, create water and electrolyte disorders and, even, lung aspiration $(4,5)$. Reviewing the literature reveals a frequency of $30 \%$ for nausea and vomiting after

\section{Corresponding author:}

Simin Nzarian, Department of Operating Room, Faculty of Nursing and Midwifery, Kurdistan University of Medical Sciences, Sanandaj, Iran.

Tel: +98.8733664654-8423, Fax:+98.8733660092, Email: Nazarian.simin@muk.ac.ir

Received: August 23, 2016, Accepted: November 01, 2016, Published: January 2017

iThenticate screening: October 31, 2016, English editing: December 27, 2016, Quality control: January 04, 2017

(C) 2017 The Authors. This is an open access article under the terms of the Creative Commons Attribution-NonCommercialNoDerivs License, which permits use and distribution in any medium, provided the original work is properly cited, the use is non-commercial and no modifications or adaptations are made. 
cataract operation (6). Despite relying on the introduction of new methods, operation and anesthesia is still abound with nausea and vomiting (7). Hypotension and the physical status of the patient play a major role in the occurrence of nausea and vomiting (8). Post-operative nausea and vomiting are one of the most common causes of dissatisfaction among patients after anesthesia $(9,10)$. Occurrence of nausea and vomiting after operation may result in dehydration, electrolyte disorders, high blood pressure, pulling of stitches, and ultimately, delayed discharge of outpatients $(11,12)$. Higher rates of post-operative nausea and vomiting are reported among the elderly and children. The type of operation (eye, ears, pharynx and nose, and thyroid) also directly impacts the frequency and occurrence of nausea (13). Cataract operations typically have a high risk of nausea and vomiting and the majority of patients are the elderly. Thus, it is necessary to use safe methods such as utilizing herbal medicines such as ginger, to control or reduce nausea and vomiting. Nausea and vomiting are controlled by anti-nausea medicines (14). Besides the medical methods to control nausea and vomiting, there are other popular non-medical relief methods (15). According to the statistics issued by WHO, nearly $80 \%$ of the world population use herbal medicines such as ginger for treatment. This figure is higher in underdeveloped countries and lower in developed countries (16). The root of ginger is used to treat nausea and vomiting $(17,18)$. Taking one gram of ginger powder is as effective as taking tranquilizing medicines to prevent nausea and vomiting after an operation (19). The Association of Herbal Medicine Products of the US has placed the ginger root at the highest level in terms of health and safety ranking. However, the appropriate amount must be prescribed with due care (20). Ginger rhizome is the root of the plant containing many active biological compounds such as Gingerols and Shogaols. These compounds have anti-nausea, anti-inflammatory, anticancer, and prostaglandins reducing effects (21). A review of the literature indicates that using ginger is completely safe and has no side-effects at all and it is as effective as taking anti-nausea medicines (22). Although there are many chemical anti-nausea medicines, they may cause different side effects for the patient. Thus, using herbal medicines such as ginger, especially for the elderly, is much more preferred and has no side effect (23). Considering the fact that those patients undergoing cataract operation are elderly, it is better to use safe herbal medicines such as ginger, rather than taking chemical anti-nausea and anti-vomiting medicines with their side effects. The present research was conducted in order to study and determine the influence of ginger on nausea and vomiting after cataract operation under general anesthesia.

\section{Material and Methods}

\subsection{Trial design and participants}

This is an interventional research conducted according to the principles of double-blind placebo-controlled randomized clinical trial. The population included the patients who were candidates for cataract operations. This research was conducted in Towhid Hospital in Sanandaj, Iran which is under the supervision of Kurdistan University of Medical Sciences in 2015.

\subsection{Inclusion and exclusion criteria}

Some of the inclusion criteria were as follows: cataract surgery candidate, volunteering to participate in the research, having no background diseases (diabetes, chronic respiratory, renal, and liver diseases and cancer, dementia, Alzheimer's and other chronic or acute disorders), no previous nausea and vomiting, and using an (general) anesthetic method with specific medicines (Propofol, Sodium Thiopental) (24). Patient's withdrawal from the research and unpredicted events such as cardiac arrest or patient's death were the exclusion criteria.

\subsection{Sample size and randomization}

Based on the statistical estimates with a $5 \%$ alpha and $20 \%$ beta and estimation of the average therapeutic difference of the two methods in the previous literature $(20 \%)$, the sample was set for 33 people for each group. Considering the possibility of the patients' withdrawal from the study, 40 people were placed in each group and finally 122 patients applying for cataract operation were selected for the 3 groups. None of the samples got out of the research in this study. As of the sampling method, the patients were selected in the first stage purposefully based on inclusion criteria. In the second stage and in accordance with the random, the patients were allocated into three groups by drawing sealed envelopes from number one to three for each of the samples. Samples divided into three groups included the first intervention group (receiving ginger capsule in a single 1 gram dose the morning before the operation), the second intervention group (receiving ginger capsule in 2 separate $500 \mathrm{mg}$ doses in the night and the morning before the operation) and the control (placebo) group. The first, second and third group finally had 40,42 and 40 members respectively.

\subsection{Intervention}

In the first intervention group, the patients were given a ginger capsule with a dose of 1 gram at 6 a.m. before the operation. As of the second group, they were given to $500 \mathrm{mg}$ doses of ginger capsule at 10 p.m. and 6 a.m. before 
the operation. In the control group, they were given a placebo capsule similar to ginger at 6 a.m. before the operation. Ginger and placebo capsules with a specific dose of 1 gram were prepared with 500 mg ginger in each one. According to the literature, this dose of the medicine reduces the intensity and frequency of nausea and vomiting $(25,26)$. After randomly selecting one of the capsules numbered from 1 to 8 and giving it to the patient and registering the number, the patient would be supervised for 6 hours checking for the incidence and severity of nausea and incidence of vomiting. After the patient randomly selects the capsule and takes it, his demographic information will be registered in the information sheet with the number of his capsule.

\subsection{Blinding}

By measuring the frequency and intensity of nausea and vomiting on the day of the operation in relation with ginger and placebo capsules, the second researcher was double-blind. This method helped us eliminate the mental influences of the researcher and patient on the results.

\subsection{Measuring outcomes}

Information was used to record the frequency and intensity of the occurrence of nausea, vomiting and other demographic specifications. The intensity of nausea was scored from 0 to 10 based on the VAS. The expected consequence (intensity and frequency of nausea) on the patient in the recovery and operative unit of Towhid Hospital of Sanandaj was studied for 6 hours after the operation by the 2nd researcher. Although exclusion from research was something inevitable, there was an attempt to prevent the patients from being excluded based on the inclusion criteria.

\subsection{Statistical methods}

The collected data were analyzed using SPSS version 20 software. We used Chi Square and Kruskal-Wallis test for the analyses of outcomes. The two-tail value of $\mathrm{p}<0.05$ was considered as statistically significant. Also, before performing the statistical analyses, the normality of the variables' distribution was examined using the K-S test.

\subsection{Research ethics}

Before beginning the research and after the confirmation of the plan by the Ethics Committee of Kurdistan University of Medical Sciences, the official consent of the ethics committee was obtained with the number IR.MUK.REC.93.132 on January 13, 2015. The enrollment of patients began on February 22, 2015, and the study continued until February 22, 2016. All the patients filled the Informed Consent form to take part in the study. The participants were informed about the objective and nature of the study, and each participant provided her written consent in her native language (Persian) prior to the study. Also, we were committed to keeping all of the participants' information confidential. For ethical considerations, if the patients were unwilling to take part in the research they were free to withdraw from the study at any time. Oral administration of ginger was safe and this matter was confirmed by the Ethics Committee of Kurdistan University of Medical Sciences.

\section{Results}

The 122 patients requiring cataract operations had no statistically significant difference with one another in terms of their age. The average age of all three groups ranged from 66.9 to 72 years old ( $p>0.05$ ). There was also no statistical significant difference between the groups in terms of the gender and length of hospitalization among those three groups $(\mathrm{p}>0.05)$. The results indicated a significant difference between the three groups based on the time of entering the recovery $(\mathrm{p}<0.001)$ (Table 1$)$, until 2 hours after operation $(\mathrm{p}<0.02)$ and until 6 hours after the operation (Table 1). This difference was caused, due to less occurrence of nausea in the group taking ginger capsules in 2 separate doses each containing $500 \mathrm{mg}$ ginger compared to the other 2 groups. The level of nausea occurrence right after entering the unit, exhibited no statistical difference among those three groups $(\mathrm{p}<0.3)($ Table 1$)$. The intensity of nausea while entering the recovery, and 6 hours after recovery in all three groups, exhibited no significant difference, while a significant difference was observed between the three groups while entering the unit $(\mathrm{p}<0.02)$ and up to 2 hours after operation $(\mathrm{p}<0.02)$ in terms of the intensity of nausea. This difference was caused due to less intensity of nausea in the group taking ginger capsules in 2 separate doses each containing 500 mg ginger compared to the other 2 groups (Table 2). The frequency of the occurrence of vomiting while entering the recovery $(\mathrm{p}=0.631)$ and 6 hours after operation $(\mathrm{p}>0.08)$ in all three groups, exhibited no significant difference. A significant difference was observed between the three groups while entering the unit $(\mathrm{p}<0.00)$ and up to 2 hours after operation $(\mathrm{p}<0.04)$ in terms of the frequency of vomiting. This difference was caused due to less frequency of vomiting in the group taking ginger capsules in 2 separate doses each containing $500 \mathrm{mg}$ ginger, compared to the 
other 2 groups. In terms of occurrence of vomiting immediately after entering the unit, no statistically significant difference was observed between the 3 groups (Table 3 ).

Table 1. Comparison the frequency of nausea occurrence among the three groups in various times (Pearson ChiSquare Test, $\mathrm{df}=2$ )

\begin{tabular}{|c|c|c|c|c|c|c|c|c|}
\hline \multirow[t]{3}{*}{ Number of Measurements } & \multirow[t]{3}{*}{ Group } & \multicolumn{6}{|c|}{ Nausea } & \multirow[t]{3}{*}{$\mathrm{p}$-value } \\
\hline & & \multicolumn{2}{|c|}{ Yes } & \multicolumn{2}{|c|}{ No } & \multicolumn{2}{|c|}{ Total } & \\
\hline & & $\mathrm{n}$ & $\%$ & $\mathrm{n}$ & $\%$ & $\mathrm{n}$ & $\%$ & \\
\hline \multirow[t]{3}{*}{ In Recovery } & Intervention 1 & 4 & 10 & 36 & 90 & 40 & 100 & \multirow[t]{3}{*}{$\mathrm{p}<0.001$} \\
\hline & Intervention 2 & 6 & 15.8 & 32 & 84.2 & 40 & 100 & \\
\hline & Control & 0 & 0 & 42 & 100 & 42 & 100 & \\
\hline \multirow[t]{3}{*}{ Entering The Unit } & Intervention 1 & 6 & 15 & 34 & 85 & 40 & 100 & \multirow[t]{3}{*}{$\mathrm{p}>0.3$} \\
\hline & Intervention 2 & 5 & 13.2 & 33 & 86.8 & 40 & 100 & \\
\hline & Control & 0 & 0 & 42 & 100 & 42 & 100 & \\
\hline \multirow[t]{3}{*}{ Two Hours After Entering The Unit } & Intervention 1 & 4 & 10 & 36 & 90 & 40 & 100 & \multirow[t]{3}{*}{$\mathrm{p}<0.04$} \\
\hline & Intervention 2 & 3 & 7.5 & 37 & 86.5 & 40 & 100 & \\
\hline & Control & 0 & 0 & 42 & 100 & 42 & 100 & \\
\hline \multirow[t]{3}{*}{6 Hours After Entering The Unit } & Intervention 1 & 1 & 2.5 & 39 & 97.5 & 40 & 100 & \multirow[t]{3}{*}{$\mathrm{p}<0.02$} \\
\hline & Intervention 2 & 5 & 13.2 & 33 & 86.8 & 40 & 100 & \\
\hline & Control & 1 & 2.4 & 41 & 97.6 & 42 & 100 & \\
\hline \multicolumn{6}{|l|}{ Total } & 122 & 100 & \\
\hline
\end{tabular}

Table 2. Comparison of nausea severity among the three groups in various times (Kruskal-Wallis test)

\begin{tabular}{|l|l|l|l|l|}
\hline Nausea & Group & Mean & SD & p-value \\
\hline In Recovery & Intervention 1 & 0.725 & 1.61 & 0.771 \\
\cline { 2 - 4 } & Intervention 2 & 0.590 & 1.39 & \\
\cline { 2 - 4 } & Control & 0.62 & 1.47 & \\
\hline Entering The Unit & Intervention 1 & 0.35 & 1.00 & 0.038 \\
\cline { 2 - 4 } & Intervention 2 & 0.68 & 1.64 & \\
\cline { 2 - 4 } & Control & 0.1 & 0.6 & \\
\hline Two Hours After Entering The Unit & Intervention 1 & 0.25 & 0.63 & \multirow{2}{*}{0.028} \\
\cline { 2 - 4 } & Intervention 2 & 0.50 & 1.48 & \\
\cline { 2 - 4 } & Control & 0.00 & 0.00 & \\
\hline 6 Hours After Entering The Unit & Intervention 1 & 0.15 & 0.48 & \multirow{2}{*}{0.101} \\
\cline { 2 - 4 } & Intervention 2 & 0.39 & 1.18 & \\
\cline { 2 - 4 } & Control & 0.00 & 0.00 & \\
\hline
\end{tabular}

Table 3. Comparison the frequency of vomiting occurrence among the three groups in various times (using Pearson Chi-Square Test. $\mathrm{df}=2$ )

\begin{tabular}{|c|c|c|c|c|c|c|c|c|}
\hline \multirow[t]{3}{*}{ Number of Measurements } & \multirow[t]{3}{*}{ Group } & \multicolumn{6}{|c|}{ Vomiting } & \multirow[t]{3}{*}{ p-value } \\
\hline & & \multicolumn{2}{|c|}{ Yes } & \multicolumn{2}{|c|}{ No } & \multicolumn{2}{|c|}{ Total } & \\
\hline & & $\mathrm{n}$ & $\%$ & $\mathrm{n}$ & $\%$ & $\mathrm{n}$ & $\%$ & \\
\hline \multirow[t]{3}{*}{ In Recovery } & Intervention 1 & 2 & 5 & 38 & 95 & 40 & 100 & \multirow[t]{3}{*}{$\mathrm{p}=0.631$} \\
\hline & Intervention 2 & 2 & 5 & 38 & 95 & 40 & 100 & \\
\hline & Control & 4 & 9.5 & 38 & 90.5 & 42 & 100 & \\
\hline \multirow[t]{3}{*}{ Entering The Unit } & Intervention 1 & 0 & 0 & 40 & 100 & 40 & 100 & \multirow[t]{3}{*}{$\mathrm{p}<0.005$} \\
\hline & Intervention 2 & 5 & 14.2 & 35 & 85.5 & 40 & 100 & \\
\hline & Control & 0 & 0 & 42 & 100 & 42 & 100 & \\
\hline \multirow[t]{3}{*}{ Two Hours After Entering The Unit } & Intervention 1 & 0 & 0 & 40 & 100 & 40 & 100 & \multirow[t]{3}{*}{$\mathrm{p}<0.04$} \\
\hline & Intervention 2 & 3 & 7.5 & 37 & 92.5 & 40 & 100 & \\
\hline & Control & 0 & 0 & 42 & 100 & 42 & 100 & \\
\hline \multirow[t]{3}{*}{6 Hours After Entering The Unit } & Intervention 1 & 1 & 2.5 & 39 & 97.5 & 40 & 100 & \multirow[t]{3}{*}{$\mathrm{p}>0.08$} \\
\hline & Intervention 2 & 5 & 14.2 & 35 & 85.8 & 40 & 100 & \\
\hline & Control & 1 & 2.3 & 41 & 97.7 & 42 & 100 & \\
\hline \multicolumn{6}{|l|}{ Total } & 122 & 100 & \\
\hline
\end{tabular}




\section{Discussion}

As the results indicated, using ginger constantly and continuously in a certain dose could be effective in reducing the frequency and occurrence of nausea and vomiting. Although its effects were different in the hours following the cataract operation, the demand for using chemical medicines was reduced. In the present study, the frequency and occurrence of nausea and vomiting in the group taking ginger in two separate doses on the night and the day before the operation, was less than the group using one gram of ginger in the morning of the day of operation and also less than the groups taking placebo. This difference was significant. In previous studies, ginger, either orally (22) and in the form of an inhaler (23) has been effective on reducing the severity of nausea and vomiting after surgery (23) (22), chemotherapy (24) and pregnancy. In fact, adding ginger to antiemetic drugs had synergic effect on the efficacy of anti-nausea and vomiting. A Mandela et al. study found that adding ginger to antiemetic had synergic significant effect in the reduction of post-operative nausea (25). In a research titled "Investigating the influence of ginger and Metoclopramide in treating nausea and vomiting caused by pregnancy, Hematzadeh et al. found that the influence of ginger, on improving the intensity and frequency of nausea and vomiting, was significantly more than Metoclopramide and (contrary to Metoclopramide) ginger had no harms or side effects for the body of those taking it (22). Another study also pointed to the efficiency of using ginger for a long time and in high doses on the frequency and intensity of nausea. In an attempt to reduce nausea and vomiting after chemotherapy, Ebrahimi et al. used ginger root powder capsules about 1 gram a day in four doses $(250 \mathrm{mg}$ each) three days before and three days after chemotherapy combined with the standard anti-nausea diet and this diet could significantly reduce the frequency and intensity of nausea (27). Some texts have pointed to the fact that ginger has no effect on reducing the frequency and intensity of nausea (20). This might be due to using ginger for a short period of time (20). While the study by Dabaghzadeh et al. because ginger was given in doses of $500 \mathrm{mg}$ in two divided doses, it could be effective in reducing nausea (26). In our research, ginger applied in a single dose on the morning before the operation had no influence on the intensity and frequency of nausea. While administration of ginger in two divided doses of $500 \mathrm{mg}$ the night before and the morning of surgery leads to a reduction in the severity of nausea after surgery $(26,27)$. The results of the current research were in line with the previous studies conducted in this field and any gaps here were mostly caused by the time and doses of taking ginger. It means that ginger will be more effective if used regularly and in separate doses.

\section{Conclusions}

As the results indicated, using ginger as a complement might reduce demand for anti-nausea chemical medicines. It could also reduce post-operative complications such as nausea and vomiting. However, some patients such as those undergoing cataract operations were elderly and using chemical medicines might have adverse effects on their health and body. Considering the effectiveness of ginger following a regular consumption pattern and in separate doses, it is recommended to use ginger in separate doses twice a day (500 $\mathrm{mg}$ each time) for a few days. It is recommended to conduct further studies before and after the operation about taking ginger in longer periods of time.

\section{Acknowledgments:}

The author wishes to thank the Deputy of Research, Kurdistan University of Medical Sciences, Sanandaj, Iran for their financial support of the project based on contract 93/132. This paper was an extract from that project. We would also like to thank all the operation room and optometry unit personnel of Towhid Hospital of Sanandaj and all those patients participating in this research.

\section{Trial Registration:}

The trial was registered at the Iranian Registry of Clinical Trials (http://www.irct.ir) with the Irct ID: IRCT2015062122853N1.

\section{Funding:}

This research was supported by the research cluster grant (93/132) from Kurdistan University of Medical Sciences, Sanandaj, Iran. The authors received no financial support for the authorship and/or publication of this article.

\section{Conflict of Interest:}

There is no conflict of interest to be declared.

\section{Authors' contributions:}

All authors contributed to this project and article equally. All authors read and approved the final manuscript. 


\section{References:}

1) Aghadavoudi O, Mirkheshti M. Evaluating the Effect of Intravenous Haloperidol and Midazolam on Postoperative Nausea and Vomiting after Strabismus Surgery (Text in Persian). Jornal Of Isfahan Medical School. 2014; 32(281).

2) Gan TJ, Meyer T, Apfel CC, Chung F, Davis PJ, Eubanks S, et al. Consensus guidelines for managing postoperative nausea and vomiting. Anesth Analg. 2003; 97(1): 62-71. doi: 10.1213/01.ANE.0000068580.00245.95. PMID: 12818945.

3) Col C, Soran A, Col M. Can postoperative abdominal wound dehiscence be predicted? Tokai J Exp Clin Med. 1998; 23(3): 123-7. PMID: 9972539.

4) Temes R, Feteiha M, Mapel D, Crowell R, Ketai L, Wernly J. Esophageal rupture after regional anesthesia: report of two cases. J Clin Gastroenterol. 1999; 28(4): 360-3. doi: 10.1097/00004836-199906000-00018. PMID: 10372939.

5) Apfel CC, Roewer N. Risk assessment of postoperative nausea and vomiting. Int Anesthesiol Clin. 2003; 41(4): 13-32. doi: 10.1097/00004311-200341040-00004.

6) Nesioonpour S, Pipelzadeh M, Mohtadi A, Rezai S, Feghhi M, Malekshoar M. A Comparative Study of Dexamethasone, Granisetron and Metoclopramide for Prevention of Nausea and Vomiting after Cataract Surgery. Bina J Ophthalmol. 2009; 14(4): 413-9.

7) Fleisher LA, Johns R, Savarese JJ, Wiener-Kronish J, Young W, Millers o. Miller's Anasthesia. Translated to Persian by: Abtahi A, Kamali F, Mahdavi NS. Tehran: Andishe Rafi; 2011.

8) McCracken G, Houston P, Lefebvre G. Guideline for the management of postoperative nausea and vomiting. J Obstet Gynaecol Can. 2008; 30(7): 600-7, 8-16. PMID: 18644183.

9) Seidy J, Farhadifar F, Ghadami N, Zandvakili F, Roshani D, Taifoori L, et al. Effect of supplemental oxygen on the incidence and severity of nausea and vomiting in the patients under cesarean surgery with spinal anesthesia. Journal of Medical University of Kurdestan. 2010; 15(2): 26-39.

10) Jahangiri M, Karimi F, Gharib A, Rahimi F. Effect of family centered care on patient's family satisfaction in intensive care unit. Journal of Chemical and Pharmaceutical Sciences. 2016; 9(2): 690-2.

11) Heidari M, Kashefi P, Rahimi M, Eskandari M. The effect of different concentrations of oxygen on postoperative nausea and vomiting after spinal anesthesia. Journal of Shahrekord Uuniversity of Medical Sciences. 2006; 8(2): 9-15.

12) Rasolabadi M, Khaledi S, Khayati F, Kalhor MM, Penjvini S, Gharib A. Scientific production of Medical Universities in the West of Iran: A scientometric analysis. Acta Inform Med. 2015; 23(4): 206-9. doi: 10.5455/aim.2015.23.206-209. PMID: 26483592, PMCID: PMC4584087.

13) Gioia L, Cabrini L, Gemma M, Fiori R, Fasce F, Bolognesi G, et al. Sedative effect of acupuncture during cataract surgery. Prospective randomized double-blind study. J Cataract Refract Surg. 2006; 32(11): 19514. doi: 10.1016/j.jcrs.2006.06.027. PMID: 17081902.

14) Fateh S, Amini M, Daliri S, Zahedian F. The effectiveness of Dexamethasone on pain, nausea and vomiting after hemorrhoidectomy. Arak University of Medical Sciences Journal. 2007; 10(3): 73-9.

15) Visalyaputra S, Petchpaisit N, Somcharoen K, Choavaratana R. The efficacy of ginger root in the prevention of postoperative nausea and vomiting after outpatient gynaecological laparoscopy. Anaesthesia. 1998; 53(5): 506-10. doi: 10.1046/j.1365-2044.1998.00369.x. PMID: 9659029.

16) Afifi FU, Wazaify M, Jabr M, Treish E. The use of herbal preparations as complementary and alternative medicine (CAM) in a sample of patients with cancer in Jordan. Complement Ther Clin Pract. 2010; 16(4): 208-12. doi: 10.1016/j.ctcp.2010.05.001. PMID: 20920804.

17) Cady RK, Goldstein J, Nett R, Mitchell R, Beach ME, Browning R. A Double-Blind Placebo-Controlled Pilot Study of Sublingual Feverfew and Ginger (LipiGesicTMM) in the Treatment of Migraine. Headache. 2011; 51(7): 1078-86. doi: 10.1111/j.1526-4610.2011.01910.x. PMID: 21631494.

18) Bluementhal M. Herbal medicine: expanded commission E monographs. New York: American Botanical; 2000.

19) Manusirivithaya S, Sripramote M, Tangjitgamol S, Sheanakul C, Leelahakorn S, Thavaramara T, et al. Antiemetic effect of ginger in gynecologic oncology patients receiving cisplatin. Int J Gynecol Cancer. 2004; 14(6): 1063-9. doi: 10.1111/j.1048-891X.2004.14603.x. PMID: 15571611.

20) Marx WM, Teleni L, McCarthy AL, Vitetta L, McKavanagh D, Thomson D, et al. Ginger (Zingiber officinale) and chemotherapy-induced nausea and vomiting: a systematic literature review. Nutr Rev. 2013; 71(4): 245-54. doi: 10.1111/nure.12016. PMID: 23550785.

21) Esteki M, Vaziri MD, Todashki H. Familliar and knowing Zingiber officinale as a drug. Danesh Ghazza. 2014; 122(11): 2-28. 
22) Hemmatzadeh S, Sadegi S, Sayyahmelli M, Pezeshky Z, Asnaashari S, Delazer A. The comparison of ginger and metoclopramid in treatment of pregnant women's nausea and vomiting. pharmaceutical sciences. 2007; 12(4): 1-5.

23) Pierre S, Whelan R. Nausea and vomiting after surgery. Continuing Education in Anaesthesia, Critical Care \& Pain. 2012; 13(1): 28-32. doi: 10.1093/bjaceaccp/mks046.

24) Sabouri Ghannad M, Hosseini M, Kazemian H, Gharib A. Alzheimer's disease and the role of infectious Agents: A review. Journal of Chemical and Pharmaceutical Sciences. 2016; 9(1): 46-53.

25) Mandal P, Das A, Majumdar S, Bhattacharyya T, Mitra T, Kundu R. The efficacy of ginger added to ondansetron for preventing postoperative nausea and vomiting in ambulatory surgery. Pharmacognosy Res. 2014; 6(1): 52-7. doi: 10.4103/0974-8490.122918. PMID: 24497743, PMCID: PMC3897009.

26) Dabaghzadeh F, Khalili H, Dashti-Khavidaki S, Abbasian L, Moeinifard A. Ginger for prevention of antiretroviral-induced nausea and vomiting: a randomized clinical trial. Expert Opin Drug Saf. 2014; 13(7): 859-66. doi: 10.1517/14740338.2014.914170. PMID: 24820858.

27) Ebrahimi M, Parsa-Yekta Z, Nikbakht-Nasrabadi AR, Hosseini M, Sedighi S, Salehi-Surmaghi MH. Ginger effects on control of chemotherapy induced nausea and vomiting. Tehran University Medical Journal. 2013; 71(6): 395-403. 